amply demonstrated last year in the case of Woo Suk Hwang, the discredited South Korean cloning researcher. Online portals discussed suspicious images and data in Hwang's papers, ultimately leading Seoul National University to pursue an investigation that exposed Hwang's fabrications. And Internet postings of allegations that Jin Chen faked digital-processing chips contributed to his dismissal from Shanghai Jiaotong University last month.

The Internet can play a particularly important role in countries such as China and South Korea that do not have adequate systems for investigating misconduct allegations. That isn't to say that countries with systems in place are totally on top of the problem, but at least they have developed some of the institutions and protocols needed to handle it.

Organizations charged with assessing allegations of scientific misconduct do exist in China, and on paper the system appears functional - but there is no evidence that it really works. China lacks an independent press to report on such matters. The very size of the country and subsequent disparate implementation of policies set in Beijing make matters worse.

In addition, the cultural importance of 'saving face' in Chinese society makes the full-frontal public attacks that tend to characterize Western misconduct allegations almost unthinkable. There are no effective provisions to protect whistleblowers, so it is hard to believe that anyone who observes misconduct would summon the courage to report it to the authorities.

It is in this climate that New Threads, a Chinese-language Internet site run by a single researcher based in San Diego, has come to play a significant role in the monitoring of scientific conduct. This arrangement is deeply problematic, however.

In China's recent history, 'bottom up' accusations have often been abused by the authorities to persecute perceived enemies of the state. This was especially true during the Cultural Revolution, when simply pasting a poster on the wall calling someone a 'bourgeois' could destroy their livelihood. The threat of innocent people being branded as 'pseudoscientists', either by a jealous rival or by the state, further clouds the misconduct picture in China.

The only real solution to this problem is a great deal more complex than hooking up to an
"There are no effective provisions to protect whistleblowers, soit is hard to believe that anyone observing misconduct would summon the courage to report it." Internet connection. It requires the establishment of independent offices in Chinese research agencies, rather like the inspector general's office at the US National Science Foundation, or the Office of Research Integrity at the US health department. The system can only operate effectively if it offers protection to whistleblowers. It also requires a new generation of scientists to be educated in what constitutes proper scientific conduct. And it needs to ensure that investigations give anyone accused the opportunity to demonstrate their innocence.

China is struggling to come to terms with these kinds of requirements in society at large, as well as within the scientific community. For a multiplicity of reasons - of which the desire for scientific progress is just one - addressing them ought to be the government's greatest priority.

\section{Last rights}

\section{Researchers have a duty to use the most humane means available of killing laboratory animals.}

S cientists who work with animals generally agree that if their subjects have to be killed, the death should be accompanied by as little fear or pain as possible. In practice, many laboratory mice and rats are currently killed with carbon dioxide gas. The method is cheap, easy, is what everyone else does, and seems painless enough. The animals are placed in a box, the gas is turned on, and the researcher can walk away.

Some veterinarians and ethicists are not convinced the method is humane, however. Although the sparse amount of investigation done on the topic is inconclusive, they consider that exposure to slowly rising levels of carbon dioxide engenders in rodents the same feeling it does in humans: blind panic. Alternatives exist and, they say, should be used (see page 570 ).

The main alternative to carbon dioxide, in places where large numbers of animals are involved, is to gas rodents with high doses of anaesthetics used on humans, such as halothane or isoflurane, as this would probably cause the animals little distress. Individual rodents can be dispatched with a manual manoeuvre known, somewhat euphemistically, as cervical dislocation, which breaks the animal's neck. Researchers have been doing this to rats and mice for decades and, done right, it is instantaneous and painless. Skill can be gained by practising on anaesthetized animals. Anaesthesia and cervical dislocation can also be used in combination.

In the United States, the institutional animal use and care committees that oversee animal research are likely to demand a "scientific justification" for breaking rodents' necks rather than gassing them. This is because most of them adhere to guidelines written by the American Veterinary Medical Association (AVMA), which requires such justification, noting that cervical dislocation may be "aesthetically displeasing to personnel" who have to carry it out. This piece of red tape often makes it sim"The main alternative to
carbon dioxide, where
large numbers of animals
are involved, is to use
high doses of anaesthetics
used on humans." pler for US researchers to stick with carbon dioxide.

Some might argue that scientists who kill mice for their research should be willing to do so with their bare hands, if that is the most humane thing to do. But there is no guarantee that it always will be, and sometimes research regulations, or the particulars of the experiment, may call for the use of one method over another. Cost is another consideration, as anaesthetic gas is more expensive, and often less readily to hand, than carbon dioxide. But everyone who makes these final decisions has a duty to carefully examine the options that are available - and to take into account what's best for the rodent, as well as for the researcher. 